\title{
Diversification in Adelomyia hummingbirds follows Andean uplift
}

\author{
JAIME A. CHAVES, ${ }^{*}+$ JASON T. WEIR $\ddagger$ and THOMAS B. SMITH*† \\ ${ }^{*}$ Center for Tropical Research, Institute of the Environment, University of California, Los Angeles, 619 Charles E. Young \\ Dr. South, La Kretz Hall, Suite 300, Los Angeles, CA 90095-1496, USA, +Department of Ecology and Evolutionary Biology, \\ University of California, Los Angeles, 621 Charles E. Young Dr. South, Los Angeles, CA 90095-1496, USA, ‡Department of \\ Biological Sciences, University of Toronto, Scarborough 1265 Military Trail, Toronto, Ontario MIC 1A4, Canada
}

\begin{abstract}
The Andes are known to have influenced speciation patterns in many taxa, yet whether species diversification occurred simultaneously with their uplift or only after uplift was complete remains unknown. We examined both the phylogenetic pattern and dates of branching in Adelomyia hummingbirds in relation to Andean uplift to determine whether diversification coincides with the chronological phases of the uplift or with recent climatic fluctuations after Andean formation. Results suggest that the genus Adelomyia originated in the central Andes in the Miocene and was found to be comprised of six deeply divergent phylogroups dating between 3.5 and $6 \mathrm{Ma}$. The most basal splits in the tree, corresponding to the most southerly distributed of the six phylogroups, diverged in the late Miocene, whereas the northern phylogroups originated during the early-to-mid-Pliocene, when the northern Andes reached heights sufficient to support Adelomyia populations. Although we provide evidence for a southern origin for the group, the subsequent diversification of the northern phylogroups did not strictly follow the hypothesized south-to-north orogeny of the Andes. Further genetic structure within phylogroups may have resulted from Pleistocene climate fluctuations after the onset of the six lineages during the Mio-Pliocene. We explore the processes that promoted diversification in the Andes and suggest that in at least some groups, divergence was coupled to Andean orogeny.
\end{abstract}

Keywords: Adelomyia, Andean uplift, hummingbirds, speciation

Received 25 August 2010; revision received 22 August 2011; accepted 1 September 2011

\section{Introduction}

The Andes in South America played an important role in the diversification of Neotropical organisms by producing a mosaic of isolated montane and inter-Andean valley habitats in which colonization and differentiation along environmental gradients could occur (Chesser \& Zink 1994; Fjeldså 1994; García-Moreno et al. 1999a; Graham et al. 2004; Dingle et al. 2006; Hughes \& Eastwood 2006; Brumfield \& Edwards 2007; Ribas et al. 2007; Milá et al. 2009; Weir 2006, 2009). Speciation may have: (i) closely followed the orogeny of each portion of

Correspondence: Jaime A. Chaves, Fax: 702895 3094;

E-mail: jaimechaves76@gmail.com the Andes (e.g. Ribas et al. 2007) or (ii) occurred long after the Andean uplift resulting from subsequent climatic changes (e.g. van den Elzen et al. 2001; Chesser 2000; García-Moreno et al. 1999b). Differentiating between these two evolutionary scenarios would provide insights into the processes that promote speciation and diversification in the Andes.

If speciation within the Andes closely followed orogeny chronologically, the oldest lineages should occur in the south and the youngest lineages in the north (Doan 2003; Picard et al. 2008), because uplift proceeded in a primarily south-to-north fashion at different geologic time scales (Gregory-Wodzicki 2000; Hartley 2003; Garzione et al. 2008). The southern portion of the central Andes (Bolivia and southernmost Peru) was uplifted 
primarily before the tertiary (Simpson 1979; Garzione et al. 2008; Hoorn et al. 2010), but the northern portions of the central Andes (central and northern Peru) experienced uplift more recently in the middle to late Miocene (Gregory-Wodzicki 2000; Hartley 2003; Garzione et al. 2008; Poulsen et al. 2010). The northern Andes (Ecuador, Colombia and Venezuela) experienced extensive uplift during the early and mid-Pliocene, especially along the eastern Cordilleras, with only a few isolated highland regions (i.e. the Perijá in Colombia and Venezuela and Mérida in Venezuela) pre-dating this period (Gregory-Wodzicki 2000; Mora et al. 2008; Hoorn et al. 2010). Accordingly, if diversification occurred during or shortly after episodes of uplift, speciation events within widespread Andean distributions should date to the Miocene or earlier in the central Andes (see García-Moreno \& Fjeldså 2000; Moritz et al. 2000) and to the first half of the Pliocene in the northern Andes.

Alternatively, the Andes may have promoted extensive diversification long after major periods of uplift. Climatic fluctuations and extensive glaciations of the late Pliocene and Pleistocene may have contributed to range expansions and diversification by providing temporary dispersal corridors through suitable habitat, followed by fragmentation into refugia (Graves 1985, 1988). Colonization of the Andes subsequent to major uplift, followed by rapid range expansion and diversification, has been reported for a number of avian groups (Pérez-Emán 2005; Weir 2006, 2009; Cadena et al. 2007; Miller et al. 2007; Weir et al. 2008; Brumfield \& Edwards 2007; Bonaccorso 2009). However, these studies focused on species with origins outside the Andes and were estimated to have reached the Andes only after they had attained their modern-day elevations (Gregory-Wodzicki 2000), sometime after the Panamanian land bridge completion in the mid-Pliocene ( 3 Ma) (Weir \& Schluter 2008; Smith \& Klicka 2010). This late arrival to the Andes would have precluded diversification driven by older uplifts and should have resulted in a decoupling of orogeny and diversification of younger taxa postdating the early Pliocene uplift of the northern Andes (García-Moreno et al. 1999a).

To differentiate between these two hypotheses for how diversification has occurred in the Andean region, an examination using taxa of strict South American origin, in which evolutionary history is exclusively linked to the Andean region, is needed. Hummingbirds are one such group as they originated in South America (Bleiweiss 1998; McGuire et al. 2007), are old enough to have been present during the early stages of Andean uplift and mountain formation (Bleiweiss 1998, McGuire et al. 2007) and have a near-exclusive Andean distribution (Bleiweiss 1998; Schuchmann 1999; Dickinson 2003). However, divergence patterns in Andean hum- mingbirds have also been attributed to ecoclimatic disturbance in Pleistocene times (García-Moreno et al. 1999a; Chaves \& Smith 2011).

Here, we address these two hypotheses to understand the current distribution of lineages in Adelomyia, a hummingbird distributed in cloud forest along the length of the Andes from Bolivia to Venezuela. A recent analysis based on a large multilocus data set confirmed six deeply divergent, reciprocally monophyletic phylogroups (Chaves \& Smith 2011): one endemic to the southern portion of the central Andes, two to the northern portions of the central Andes and three to the northern Andes. In this study, we first utilize a novel molecular phylogenetic dating approach to determine whether diversification occurred simultaneously with or after the most recent uplift phases of the central and northern Andes. Second, we investigate the direction of dispersal in Adelomyia, specifically testing the south-tonorth hypothesis using biogeographical analyses and tree-topology testing. Third, we attempt to understand diversification driven by climatic fluctuations using recent population genetic estimates. Finally, we attempt to relate divergence patterns to specific Andean geographical features.

\section{Methods}

\section{Genetic data and phylogenetic reconstruction}

All Adelomyia DNA sequences were generated as part of previous phylogenetic studies (Chaves et al. 2007; Chaves \& Smith 2011). Sequences from 36 individuals, representing each of the major phylogroups (one individual for clade $E$ and two to ten individuals in each of the other phylogroups) representing unique haplotypes for groups with complex geographical ranges were included (see Appendix S1, Supporting Information). We followed phylogroup designation as in Chaves \& Smith (2011): clade $A$ : corresponding to the subspecies inornata from the Andes of Bolivia; clade $B$ : corresponding to subspecies melanogenys and chlorospila from the eastern Cordillera of Peru; clade C: corresponding to maculata subspecies from northern portion of the western Cordillera of Peru and west Andes of Ecuador and coastal Ecuador; clade $D$ : comprising of four subspecies melanogenys, cervina, connectens and debellardiana from the eastern Cordillera in Ecuador and northern Andes of Colombia and Venezuela; clade E: corresponding to aenosticta subspecies from the coastal Cordilleras in Venezuela; and clade F: corresponding to melanogenys subspecies restricted to the northern section of the eastern Cordillera in Colombia. A near-complete genus level phylogeny of hummingbirds (McGuire et al. 2007) placed Aglaiocercus as sister to Adelomyia, and we 
therefore included Aglaiocercus kingi as the outgroup in our analysis. For each individual, three mtDNA markers were used, the 2 subunits of the ATPase mitochondrial gene (ATPase 6 and 8: $852 \mathrm{bp}$ ), cytochrome $b$ (Cyt $b: 1143 \mathrm{bp}$ ) and NADH dehydrogenase subunit 2 (ND2: $1041 \mathrm{bp})$. We performed phylogenetic reconstruction and provided nodal support for this concatenated data set via maximum likelihood (ML) analyses using PAUP* v4b10 (Swofford 2000), Bayesian (BA) inference in MrBayes v3.1.2 (Ronquist \& Huelsenbeck 2003) and BEAST v1.4.4 (Drummond \& Rambaut 2007) (see Appendix S2, Supporting Information). ML analyses were conducted under the appropriate model parameter values obtained from jModelTest v0.1.0 (Posada 2008) for the concatenated mtDNA data set $(\mathrm{GTR}+\Gamma+\mathrm{I})$. We assessed clade support via 100 bootstrap pseudo-replicates, with an initial tree generated by neighbour joining. BA analyses were conducted in MrBayes, with a mixed-model with a partition by gene assigning independent models of evolution to each gene as in Chaves \& Smith (2011). All parameters were unlinked between partitions, except topology and branch lengths on the mtDNA extended data set. We estimated dates for all the nodes using the most well-supported tree.

\section{Molecular clock and divergence time estimates}

The validity of a global molecular clock was tested on the concatenated mtDNA data from a subset of 17 samples by comparing likelihoods generated in PAUP* v4b10 (Swofford 2000) with and without a clock assumption via a likelihood ratio test (Felsenstein 1981) implemented in jModeltest. A global clock was rejected $(P<0.001)$ for our mtDNA data set; thus, we estimated divergence times of the major clades under a relaxedclock framework in BEAST v1.4.4 (Drummond \& Rambaut 2007) and run for 10 million generations with a Yule tree prior and sampled every 1000 generations. Good stationary, high effective sample sizes (ESS > 2000) and 95\% highest posterior densities (HPDs) were observed for all parameters in TRACER v1.3 (Rambaut \& Drummond 2003). A consensus tree with divergence times was obtained from the 10000 generated trees, after discarding the first 2500 as burn-in.

Fossil calibrations are not available for Adelomyia. We used two approaches to calibrate our BEAST tree. First, we applied the average molecular rate of 0.0105 substitutions/site per lineage per million years obtained using the GTR $+\Gamma$ model for Cyt $b$ from a large data set of 74 avian calibrations spanning 13 orders (Weir \& Schluter 2008). One of the calibrations in this data set was for a related hummingbird (Lampornis), which had a rate $(0.0086)$ that was similar to the mean value for the entire data set. To determine the validity of applying the Cyt $b$ rate to the entire mtDNA data set, we compared model-corrected (GTR $+\Gamma+$ I model) genetic distances of Cyt $b$ to the combined data set of ND2 and ATPase 6 and 8. Model-corrected genetic distances of the combined data set (excluding Cyt $b$ ) were closely correlated $(r=0.9)$ and had a 9:10 ratio to corrected distances for Cyt $b$ (Fig. 1). Given the rates are similar across these genes, we used the Cyt $b$ rate for our entire mitochondrial data set. As a second approach, we used an internal biogeographic-based calibration for Adelomyia based on the assumption that the eastern Cordillera of the Andes in Colombia was first colonized immediately following its uplift. Adelomyia occurs primarily between 1300 and $2500 \mathrm{~m}$ in Colombia (Hilty \& Brown 1986). Elevations $>1300 \mathrm{~m}$ needed to support $A$ delomyia were achieved sometime between 5 and $3 \mathrm{Ma}$ when the eastern Cordillera experienced most of its uplift (Gregory-Wodzicki 2000; Hoorn et al. 2010). Clade $F$ is the oldest phylogroup endemic to this cordillera, and we used the node connecting clade $F$ to other Adelomyia phylogroups as a calibration point.

We used the following cross-validation method to determine a suitable date for calibration of this node. First, a tree was generated in BEAST that included Cyt $b$ sequences for one individual from each of the six Adelomyia phylogroups and for the 47 best-supported external avian calibrations reported by Weir \& Schluter (2008). Because we do not know the exact date at which elevations appropriate for clade $F$ were available, we did not condition the cross-validation on a specific date, but tested a range of potential dates from 0 to $10 \mathrm{Ma}$ in 0.1 million year intervals. For each date, we fixed the age of the node connecting clade $F$ and asked how well that calibration date predicted the 47 avian calibrations in the tree. The fit was calculated using SS, a statistic that measures the sum of the squared differences (after scaling, see details in Weir \& Schluter 2008) between each of the other 47 predicted node ages and their associated calibration dates. The date for clade $F$ with the lowest $S S$ values (the date that best predicts the other 47 calibrations) was used as the calibration date.

\section{Direction of dispersal in Adelomyia and the south-to-north hypothesis}

If diversification was closely tied to Andean orogeny, then colonization events in Adelomyia should have occurred in an approximately south-to-north (older to younger regions) direction. Provided there was no extinction, back colonization or subsequent vicariant events following the initial south-to-north colonization, then the expected phylogeographical tree will have a pectinate topology, with the most southerly clade branching first at the base of the tree (close to the root) 
(a)

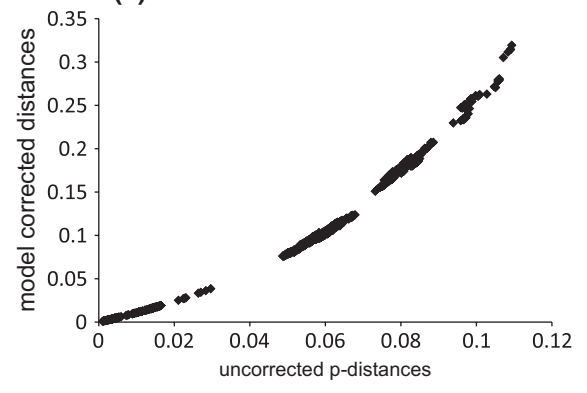

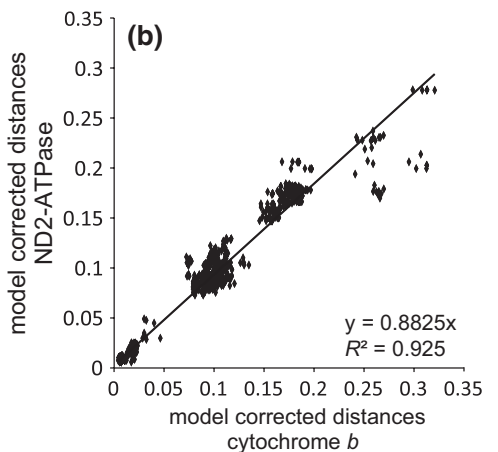
cytochrome $b$

Fig. 1 (a) Saturation plot for the three-gene data set; (b) relationship between maximum likelihood model corrected distances for cytochrome $b$ only and the remaining two mitochondrial genes.

and the youngest taxa occupying the most nested level of the tree. For Adelomyia, the proposed hypothesis assumes that the most southerly phylogroups, clade $A$, should branch first, followed by clades $B, C, D, F$ and finally $E$.

We tested the south-to-north hypothesis using the parametric Swofford-Olsen-Waddell-Hillis test (SOWH: Goldman et al. 2000; Huelsenbeck et al. 1996). This test uses a maximum likelihood approach to assess whether the optimal topology is significantly better than the expected topology under the south-to-north hypothesis. The test was implemented with one representative individual from each of the major clades. A maximum likelihood tree was generated in PAUP* and compared with two alternative topologies: the pectinate south-tonorth topology and a random topology. For both comparison topologies, maximum likelihood estimates of branch lengths were generated.

The SOWH test was implemented as follows. Null distributions for the log-likelihood ratio test statistic were estimated from 500 pseudo-replicated DNA data sets, each $3036 \mathrm{bp}$ in length (corresponding to the length of our actual mtDNA data set). Simulated sequence data sets were obtained in Seq-Gen 1.2.7 (Rambaut \& Grassley 1997) with the SG Runner graphical interface 1.5.2 (Wilcox 2004) under the GTR + $\Gamma+\mathrm{I}$ model of sequence evolution. The optimal tree for each of the 500 simulated data sets was found using PAUP* for each of the two proposed constraints of Andean diversification. The null distribution for each hypothesis was formed by calculating the difference in tree length between the constrained and unconstrained topology and tested for significance by comparing the difference to the null distribution.

\section{Biogeographical analyses}

We used Bayes-DIVA implemented in Statistical DIVA (S-DIVA 2.0 renamed RASP, Yu et al. 2010) to elucidate the ancestral geographical distributions of Adelomyia phylogroups. Bayes-DIVA determines the probability of each ancestral geographical region for each node averaged over all sampled trees derived from MCMC, implementing the methods of Nylander et al. (2008) and Harris \& Xiang (2009). We loaded 2000 trees previously produced in MrBayes v3.1.2 (Ronquist \& Huelsenbeck 2003) using a total of 36 samples and ran the analysis for 50000 cycles using 10 chains. We assigned five geographical regions: (1) southern portion of the central Andes (north limit at Cordillera of Vilcanota in south Peru), (2) central Andes of Peru (north limit North Peruvian Low/Marañón River Valley), (3) western Andes of Ecuador (south limit North Peruvian Low/Marañón River Valley), (4) eastern Andes of Ecuador and northern Andes in Colombia and Venezuela, and (5) coastal Cordilleras of Venezuela (western limit Barquisimeto Depression: Serranía de Aroa, San Luis and the Cordillera de la Costa). These areas are separated by deep river valleys in the Andes (Weir 2009; Chaves \& Smith 2011) and/or represent ecologic regions known to be a reflection of historical geologic patterns (e.g. WWF ecoregions, Olson et al. 2001). The outgroup genus Aglaiocercus occurs in each of the geographical regions occupied by Adelomyia and was accordingly coded (1-2-3-4-5). The maximum number of areas was constrained to 4 ( $\max$ areas $=4)$, but we also explored the importance of changing the max. areas (setting number max areas = 2, 3, and 5). Similarly, we explored (i) splitting northern Andes into west, central Andes of Colombia, eastern Andes of Ecuador-Colombia-Venezuela, (ii) splitting northern Andes in Andes EcuadorColombia and Andes of Venezuela, (iii) lumping western Andes of Ecuador with the rest of northern Andes. None of these alternative groupings altered marginal probabilities at deeper nodes.

\section{Population genetics methods}

We estimated several genetic diversity statistics for each of the Adelomyia phylogroups separately using mitochondrial ATPase 6 and 8 from a total of 190 
Table 1 Population genetic estimates for the six Adelomyia phylogroups. Sample size $(n)$, haplotype number $(H)$, haplotypic diversity $(h)$, nucleotide diversity $(\pi)$ and Fu's $F_{\mathrm{s}}$ estimates from mtDNA ATPase genes $\left({ }^{* *} P<0.01,{ }^{*} P<0.05\right)$

\begin{tabular}{lrrrrr}
\hline Lineage & $n$ & $H$ & \multicolumn{1}{l}{$h$} & $\pi$ & Fu's $F_{\mathrm{s}}$ \\
\hline Clade $A$ & 22 & 10 & $0.7489 \pm 0.0950$ & $0.004492 \pm 0.002620$ & $-1.46515 \mathrm{~ns}$ \\
Clade B & 32 & 15 & $0.9214 \pm 0.0275$ & $0.005317 \pm 0.002987$ & $-3.56479^{*}$ \\
Clade C-Andes & 40 & 14 & $0.8474 \pm 0.0367$ & $0.002060 \pm 0.001357$ & $-7.88271^{* *}$ \\
Clade C-coast Ec & 13 & 9 & $0.8718 \pm 0.0913$ & $0.0022130 \pm 0.002097$ & $-3.77624^{* *}$ \\
Clade D & 62 & 44 & $0.8474 \pm 0.0367$ & $0.009754 \pm 0.005079$ & $-24.80161^{* *}$ \\
Clade $F$ & 7 & 5 & $0.9048 \pm 0.1033$ & $0.019003 \pm 0.011074$ & $2.70401 \mathrm{~ns}$ \\
Clade $E$ & 14 & 8 & $0.8681 \pm 0.0764$ & $0.022313 \pm 0.011814$ & $3.81130 \mathrm{~ns}$ \\
\hline
\end{tabular}

individuals [Accession no. reported in Chaves \& Smith (2011)]. These included: (i) number of haplotypes (H), (ii) haplotypic diversity ( $h$ ) and (iii) nucleotide diversity estimates as the average of pairwise nucleotide differences per site between two sequences $(\pi)$ using Arlequin v3.0 (Excoffier et al. 2005) (Table 1). To examine the traces of population expansion, we used Fu's $F_{\mathrm{s}}$ statistic (Fu 1997), which is particularly effective at detecting sudden changes in effective population size by measuring departures from neutrality in situations characterized by an excess of rare alleles and young mutations (Fu 1997; Ramos-Onsins \& Rozas 2002). Significance of $F_{\mathrm{s}}$ values was evaluated with 1000 random permutations in Arlequin v3.0, where large negative values of $F_{\mathrm{s}}$ reject population stasis as an indication of deviation caused by population growth and/or selection (Fu 1997; Ramos-Onsins \& Rozas 2002). We separated clade $C$ individuals into two groups based on geographical area, coastal Ecuador and Andes, to further explore the different population genetic patterns reported by Chaves et al. (2007). To represent intraspecific phylogenies, we constructed minimum-spanning networks of absolute distances between mtDNA haplotypes using the molecular variance parsimony algorithm (Excoffier \& Smouse 1994) implemented in Arlequin v3.0.

\section{Results}

Divergence times, cross-validation analysis and diversification hypothesis testing

Dates of divergence between 3.6 and 5.4 Ma were supported for the origin of clade $F$ from the Santander region by the cross-validation analysis, with a date of 4.5 Ma receiving the strongest support (Fig. 2). These dates correspond closely with the origin of the eastern Cordillera of Colombia between 5 and $3 \mathrm{Ma}$ and provide strong support for a close coupling of orogeny and species diversification. We then calibrated clade $F$ with the $4.5 \mathrm{Ma}$ date and obtained a molecular rate of $2.24 \%$

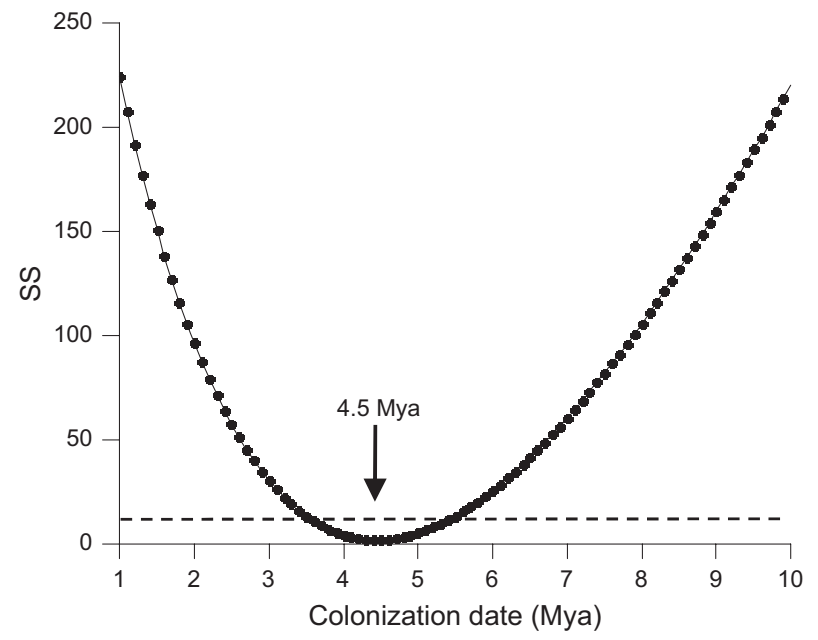

Fig. 2 Results of cross-validation analysis for colonization date of the eastern Colombian Cordillera. The best-supported date $(4.5 \mathrm{Ma})$ is shown by the arrow. Values below the dashed line (3.6-5.4 Ma) are not rejected by cross-validation.

(based on a GTR $+\Gamma$ divergence of $10.06 \%$ ) or $1.12 \% /$ lineage/ $\mathrm{My}$, a rate very similar to the average avian rate of $1.05 \% /$ lineage/My (Weir \& Schluter 2008). Node ages are reported after calibrating with both the average avian rate as well as the $4.5 \mathrm{Ma}$ date for clade $F$ (Fig. 3a).

Our analysis places the origin of Adelomyia in the Miocene. The six phylogroups of Adelomyia were formed between late Miocene and mid-Pliocene (6.03.4 Ma) (Fig. 3a and Appendix S2, Supporting Information). The first split corresponded to the southern clade $A$ from Bolivia at the Miocene-Pliocene boundary 6.0 Ma (Node I: 95\% HPD: 4.7-7.1 Ma). The rest of the phylogroups north of clade $A$ have diverged rapidly during a window of time spanning from 5.2 and 2.7 Ma corresponding to the most recent Pliocene uplift phase. In particular, clade $D$ from eastern Andes of Ecuador and Colombia diverged in the early Pliocene around 4.4 Ma (Node III: 95\% HPD: 3.7-5.2 Ma), clade $E$ from coastal Cordilleras in Venezuela around 4.1 Ma (Node IV: 95\% HPD: 3.4-4.8 Ma), clade $B$ from the eastern 

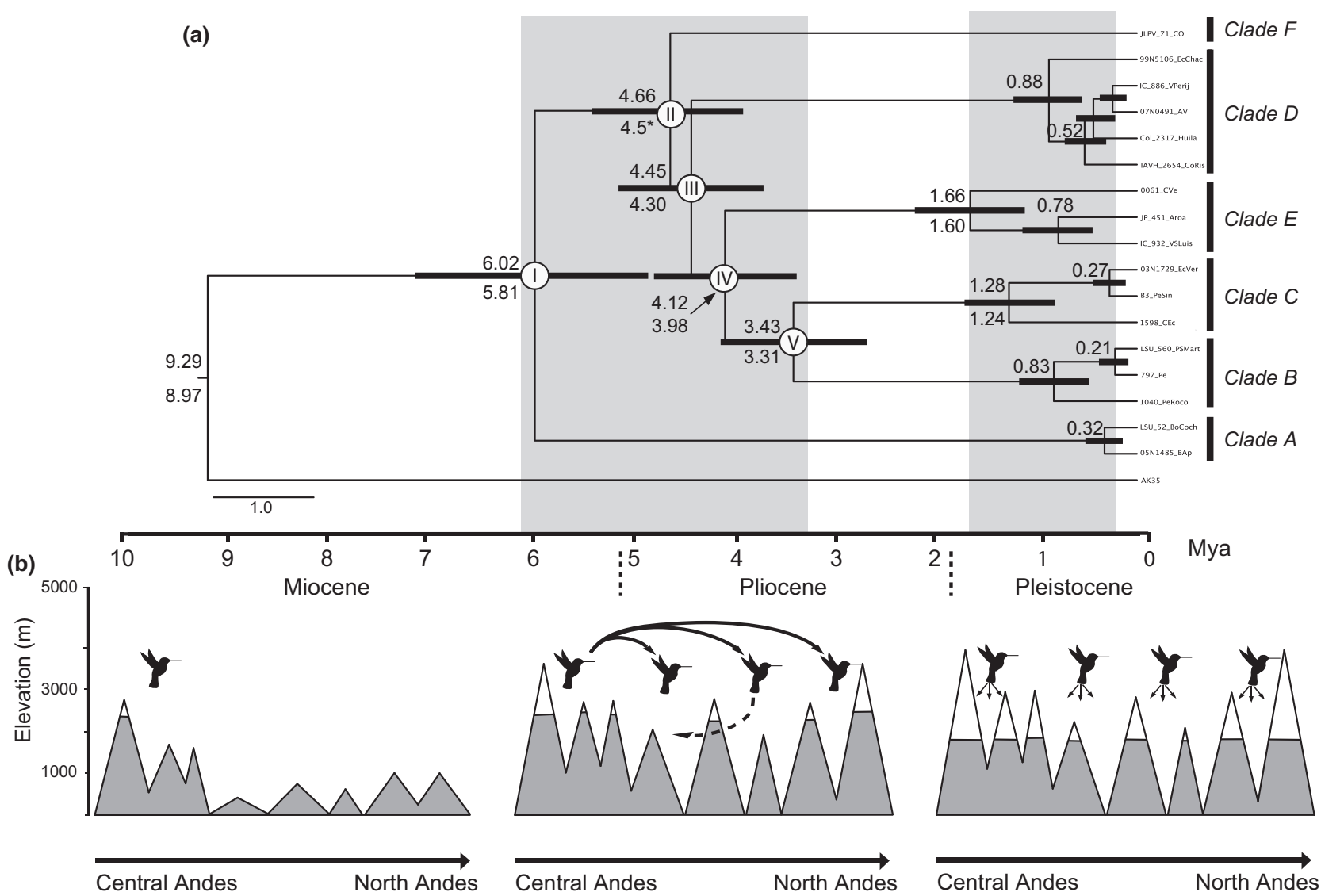

Fig. 3 Divergence time estimates and speciation scenarios in Adelomyia (time scale is in millions of years). (a) The Bayesian Inference chronogram from BEAST based on the mtDNA combined data set (ND2, ATPase and cytochrome $b$ ). Dates above nodes, the scale bar and $95 \%$ credible interval (C.I. is represented by black bars at nodes) use the mean published rate for cytochrome $b$ for a large data set of avian calibrations (Weir \& Schluter 2008). Dates below nodes were obtained by assuming that clade $E$ (denoted with asterisk) colonized the eastern Cordillera in Colombia at 4.5 Ma when elevations sufficient for this lineage were achieved. Shaded areas in the tree show windows of time when major diversification occurred. For visual purposes, we did not collapse Nodes III and IV. (b) Diagram of the chronological origin of Adelomyia lineages: (left panel) origin of genus Adelomyia in south central Andes during early Miocene; (central panel) expansion of lineages from south to north with isolation of clade $A$ in the south, once the Andes in the north obtained elevations able to support montane hummingbirds during Mio-Pliocene uplift (with additional southern dispersal form the north in clades $C$ and $B$ ); (right panel) subsequent intralineage divergence during climatic fluctuation in the Pleistocene.

Andes of Peru and clade $C$ from the western Andes of Peru and Ecuador were estimated to have diverged around 3.4 Ma (Node V: 95\% HPD: 2.7-4.1 Ma), and clade $F$ from eastern Andes of Colombia originated around 4.6 Ma (Node II: 95\% HPD: 3.8-5.3 Ma). Additionally, we found reciprocally monophyletic subdivisions dating after 1.6 Ma within several phylogroups (Fig. 3). All other haplotypes within phylogroups date to the Pleistocene. This window of time coincides with intense climatic fluctuations at high altitudes (Hooghiemstra \& van der Hammen 2004).

According to our topology, the first cladogenesis event separated the southernmost phylogroup (clade $A$ ) from the other phylogroups (clades $B$ to $F$ ). The Bayesian topology of the five northern phylogroups did not strictly follow the expected south-to-north pectinate pat- tern, but the SOWH test failed to reject the south-tonorth topology for our data $(P=0.09)$, so we are unable to rule out a strict latitudinal progression. The SOWH test, however, did reject the random topology $(P<0.001)$.

\section{Ancestral geographical distributions}

The Bayes-DIVA analysis (Fig. 4) provided support for a southern origin of Adelomyia as shown by the marginal probability at the well-supported basal Node I (region 1, $P=66 \%$ ) with other geographical areas showing lower probabilities (region 5, $P=15 \%$ and regions $1-5, P=9 \%$ ). Also, this analysis suggests that one dispersal event occurred from the northern Andes (geographical region 5, Node II $P=81 \%$ ) back to the 


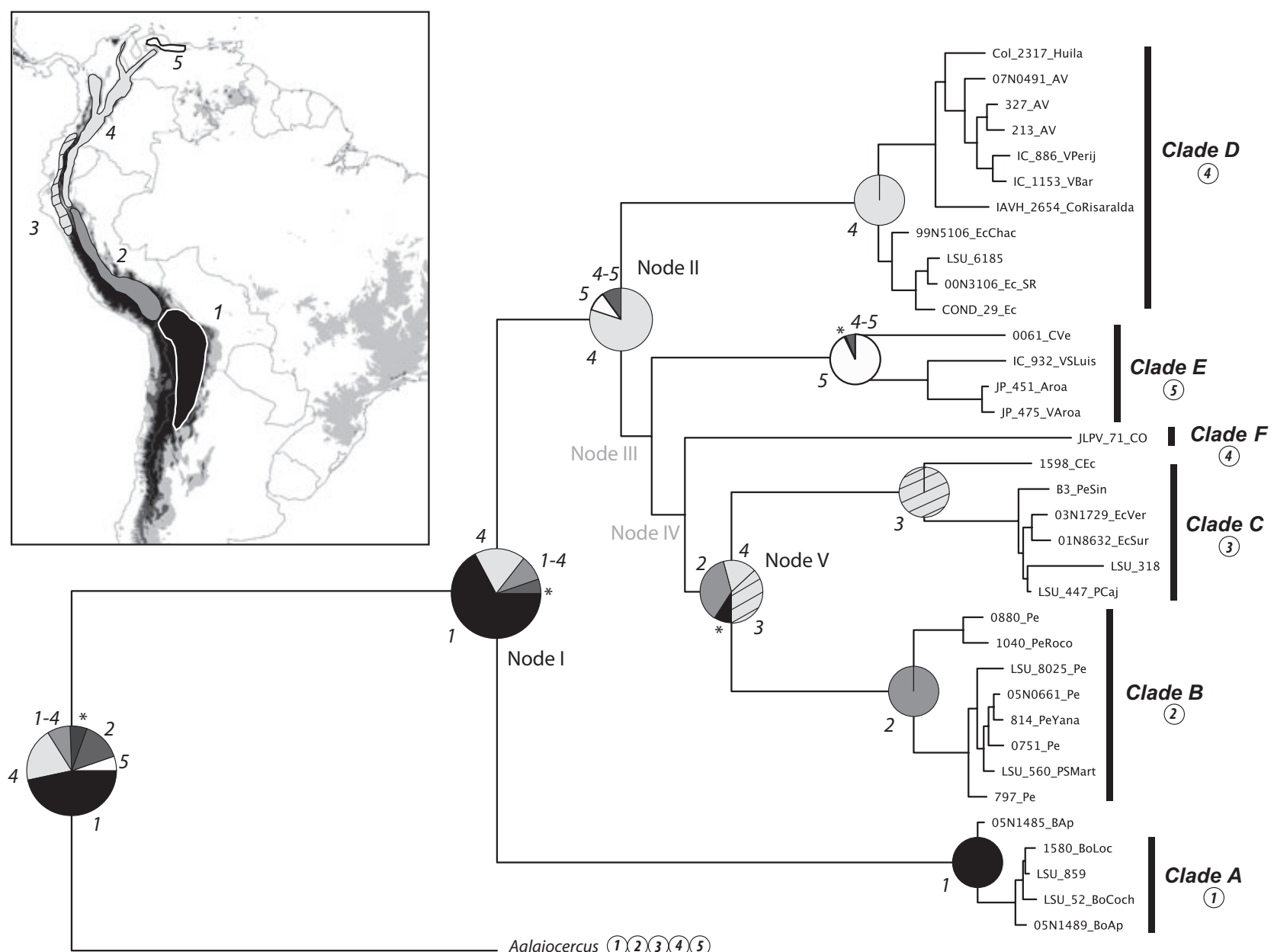

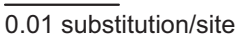

Fig. 4 Biogeographical analysis of Adelomyia lineages. Node pie charts show the relative probabilities of alternative biogeographical distributions obtained by integrating dispersal-vicariance analysis (Bayes-DIVA) optimizations over the 2000 Bayesian trees. Pie charts indicate well-supported nodes (PP > 0.95, ML > 70: modified from Chaves \& Smith (2011)), and colours reflect the probability of the area of origin according to the biogeographical delimitation as in map (Inset) Biogeographical regions: 1, southern portion of central Andes; 2, central Andes; 3, west Andes Ecuador/northwest Andes Peru; 4, northern Andes; 5, coastal Venezuela. Asterisks depict multiple areas. Circled numbers at each clade denote biogeographical regions used in the analysis. For visual purposes, we did not collapse Nodes III and IV.

central Andes (geographical region 2), as depicted in the sequence of nodes leading from Node II to Node V, although no support was found for nodes III and IV.

\section{Population genetic estimates}

Fu's $F$ tests of neutrality for the phylogroups were significant, with large negative values for clades $B, C$-coast, $C$-Andes and $D$ (Table 1). These negative values suggest population expansion in these three phylogroups. The $F_{\mathrm{s}}$ value for clade $A$ was also negative $\left(F_{\mathrm{s}}=-1.465\right.$; $P=0.21$ ), but not significantly so. However, we were unable to obtain samples from the southern half of the geographical range, so further sampling is necessary to verify a signature of range expansion. Importantly, these four phylogroups with negative $F_{\mathrm{s}}$ values also have the largest geographical ranges, as might be expected following population expansion episodes. Populations from the geographically restricted clades $E$ and $F$ in the northern Andes had positive $F_{\mathrm{s}}$ values suggesting population stability. Adelomyia phylogroups show overall high levels of haplotype diversity $(h)$ (Table 1 ), as depicted by the minimum-spanning networks (Fig. 5). In contrast, nucleotide diversity $(\pi)$ was considerably higher for the two groups with restricted ranges from the northern Andes (clades $E$ and $F$ ) compared with the groups with larger ranges to the south, rejecting sudden expansion in effective population size in these two groups. 


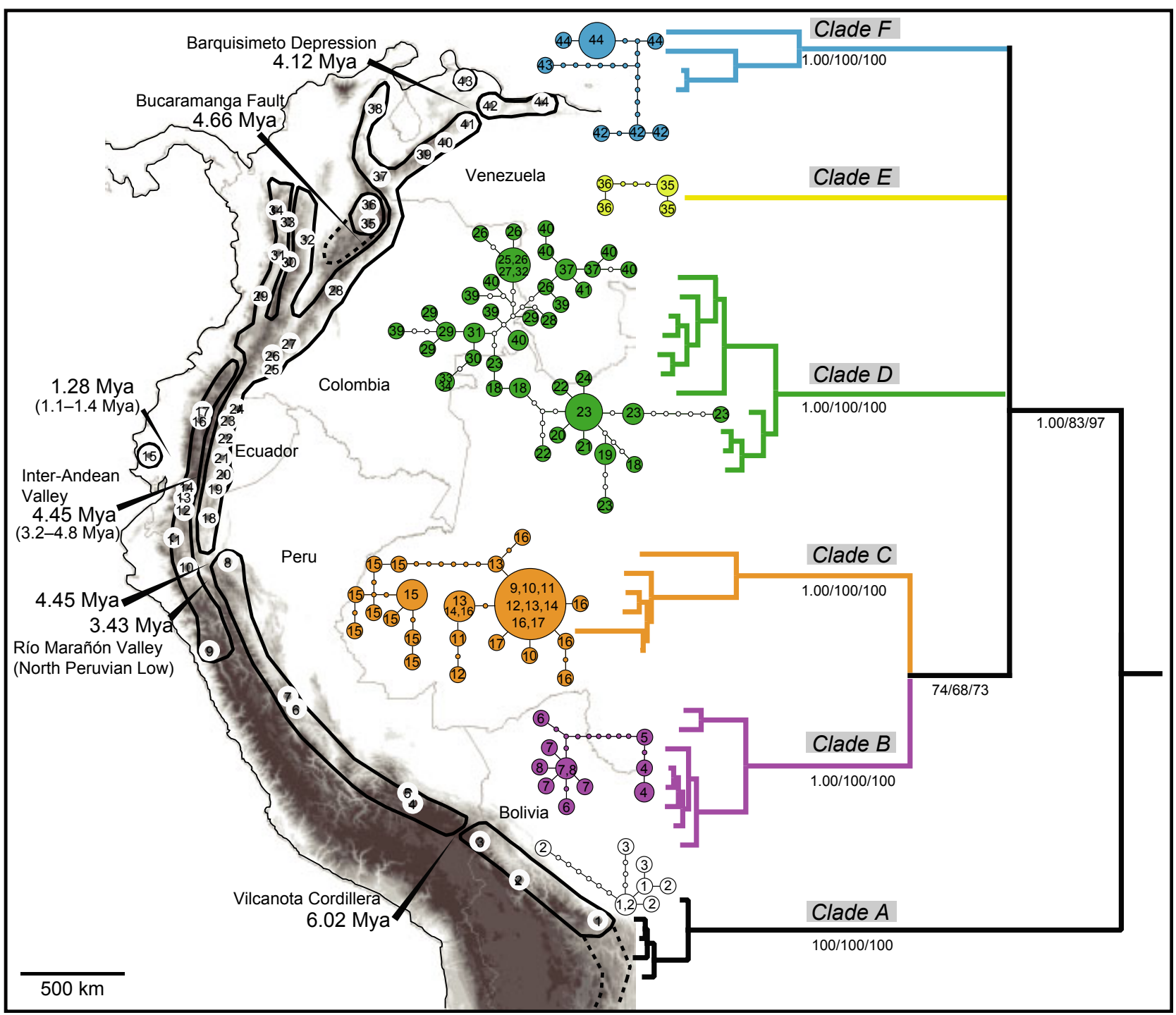

Fig. 5 Geographical distribution of Adelomyia lineages in the Andes. Arrows depict geographical barriers to dispersal, and numbered dots refer to sampling sites. Molecular divergence time estimations for Adelomyia phylogroups are represented at their corresponding geographical range (mean substitution rate from multitaxa cross-validation test-see text). Divergence times in parenthesis are taken from Chaves et al. (2007). Minimum-spanning networks of absolute genetic distances and phylogenetic tree are based on ATPase 6 and 8 markers from 190 individuals. Each circle represents a haplotype, with size proportional to the haplotype's frequency in the population. Blank circles represent missing haplotypes. Nodal support on tree corresponds to posterior probability/ML bootstrap/MP bootstrap (modified from Chaves \& Smith 2011).

\section{Discussion}

\section{Origin of genus Adelomyia and direction of dispersal}

Three lines of evidence suggest an origin for Adelomyia in the southern part of the tropical Andes. First, our dating suggests that Adelomyia and Aglaiocercus (Andean Clade representatives: McGuire et al. 2007) last shared a common ancestor in the mid-Miocene $(\sim 9.2 \mathrm{Ma})$ (Fig. 3a), at a time when paleoelevations (2000-2500 m) and plant communities able to support montane hum- mingbirds were restricted almost completely to the south portion of the central Andes (Bolivia south Peru) (Fig. $3 \mathrm{~b})$. Second, Bayes-DIVA analyses suggest a southern origin for the basal Adelomyia node (Fig. 4), in which the Bolivian Andes received the highest probability values for the ancestral reconstruction. Finally, the basalmost split at $6 \mathrm{Ma}$ occurs between the Bolivian clade $A$ and all other northern phylogroups (Fig. 3a), a pattern which is consistent with a southern origin followed by northward expansion into the rest of the Andes and lowland Cordilleras in Venezuela during their Pliocene 
uplift (Fig. 3b). The close spacing of nodes II to $\mathrm{V}$ in the phylogenetic reconstruction (Fig. 3a) precludes reconstruction of the exact sequence of diversification events in the northern portion of central and northern Andes, but does suggest that phylogroups in the north arose rapidly during a short period in the mid-Pliocene. There are several possible scenarios explaining the diversification of northern lineages. The first possibility is that the south-to-north topology is correct, and the true tree cannot be recovered because of rapid expansion through the northern Andes. Alternatively, the Peruvian form (proto-clade $B$ ) may have colonized the northern Andes several times, with the first colonization events (one or more) producing clades $F, E$ and $D$ and the last colonization event producing clade $C$. However, this reconstruction is not supported by the Bayes-DIVA analysis (Fig. 4). The results of the Bayes-DIVA analysis instead suggest a third scenario, a northern expansion through the central Andes that produced clades in the northern Andes $(E, F$, and $D)$ followed by a back colonization that produced the more southerly distributed clades $B$ and $C$ (Figs $3 \mathrm{~b}$ and 4). All of these scenarios coincide with a vigorous uplift in the Andes of Peru northwards to Venezuela reaching elevations above $2500 \mathrm{~m}$ (Noble et al. 1990; Picard et al. 2008; Poulsen et al. 2010; Hoorn et al. 2010), facilitating the dispersal of this group northwards. While a few isolated portions of the northern Andes had obtained important elevations $(>2000 \mathrm{~m})$ during the Miocene (Mérida Andes) (Hoorn et al. 2010), the timing of colonization of the north (Fig. 3) suggest these regions were reached only after lineages moved northwards from a southern region following widespread uplift in the Pliocene.

In contrast to the inferred south Andean origins for Adelomyia, phylogeographical studies of other Neotropical montane bird species suggest expansion from northern regions in Middle America south through the Andes (Myioborus-, Pérez-Emán 2005; Buarremon-, Cadena et al. 2007; Myadestes-, Miller et al. 2007; Chlorospingus ophthalmicus-, Weir et al. 2008; Cyanolyca-, Bonaccorso 2009). However, these studies included taxa that had Mesoamerican origins outside the Andean region. The estimated dispersal time to Andean regions for many groups of Mesoamerican origin occurred primarily after the Panamanian land bridge was completed in the mid-Pliocene ( 3 Ma) (Weir et al. 2009; Smith \& Klicka 2010), a time when the Andes had nearly reached their modern elevations (Gregory-Wodzicki 2000). The late arrival of Mesoamerican avian groups to the Andes would have precluded diversification driven by the south-to-north chronological uplift. Adelomyia, thus, presents the first documented case of diversification tracking the temporal Andean uplift phases in birds.

\section{Pleistocene phylogeography}

Our intraspecific analysis found high haplotypic diversity $(h)$ within phylogroups, supporting the hypothesis that the six phylogroups have been isolated for a long time with little or no gene flow between them. Low effective populations sizes, low nucleotide diversity $(\pi)$ and evidence for demographic expansion (Fu's $F_{\mathrm{s}}$ ) are all indications that clades $B, C$, and $D$ suffered past genetic bottlenecks followed by population expansion. Most uplift phases in the Andes pre-date the onset of the Pleistocene, thus the high phylogenetic diversity of haplotypes within Adelomyia phylogroups (Figs 3-5) is most likely due to climatic fluctuations well after the formation of these lineages in the Miocene-Pliocene. Population contraction and fragmentation at higher elevations could be the result of marked dispersal barriers created by the lowering of glaciers and severe elevational compression of montane vegetation zones in response to overall cooling temperatures (van der Hammen 1989; Hooghiemstra \& van der Hammen 2004; Hooghiemstra et al. 2006). In contrast, the higher nucleotide diversity $(\pi)$ found in clades $F$ and $E$ indicate long-term demographic stability and in combination with the suggested model of population stasis (Fu's $F_{\mathrm{s}}$ ) suggest that coastal Venezuela and the northern portion of the northern Andes in Colombia could have served as an ecoclimatic refugia maintaining isolated populations that were relatively unaffected by Pleistocene events. Accordingly, these regions may have harboured stable effective population sizes in regions where disturbance was moderate (see GarcíaMoreno et al. 1999a; Brumfield \& Capparella 1996), while the rest of the phylogroups suffered from possible range contractions and fragmentation during Pleistocenic climatic cycles.

\section{Biogeographical barriers}

Geographical discontinuities found along the Andes are known to influence dispersal events, thus promoting differentiation (Cracraft 1985; Stattersfield et al. 1998; Weir 2009). This is also the case in Adelomyia hummingbirds, where genetic breaks between adjacent phylogroups generally corresponded to deep valleys (Chaves \& Smith 2011). The geographical limits between clades $A$ and $B$ coincide geographically with the Cordillera of Vilcanota and Inambari River Valley in south Peru (Fig. 5). This region is known to demark species distributional limits in other avian groups (see Stattersfield et al. 1998; Fjeldså et al. 1999), perhaps due to drastic environmental and climatic transitions in this region (Fjeldså et al. 1999; Buermann et al. 2008), which have recently been proposed to act as environmental barriers 
limiting species ranges in other Andean birds (Graham et al. 2010).

Phylogeographical breaks in Adelomyia in the northern portion of the central Andes correspond with the North Peruvian Low (NPL) and the Marañón River Valley (Fig. 5), believed to be one of the most important barriers affecting migration and distribution of Andean birds along the eastern slope of the Andes (Parker et al. 1985; Bates \& Zink 1994; Johnson \& Jones 2001; Miller et al. 2007; Weir 2009; Chaves \& Smith 2011). Whether the NPL was formed during the late Pliocene (Kroonenberg et al. 1990), coinciding with the phylogenetic breaks between Adelomyia clades $A, B$ and $D$, and documented in other taxa (Bates \& Zink 1994; Miller et al. 2007; Weir 2009), or is much older (Räsänen et al. 1993), the permeability of this barrier during the mid-Pliocene may have allowed populations of Adelomyia to expand northwards. However, the maintenance of the genetic identity of these three phylogroups in such close geographical proximity on either side of the NPL is a clear example of the isolating effects of this barrier.

The divergence time of clade $F$ from Santander strongly suggests a link to the orogenic activity along the Bucaramanga Fault during the major Andean deformation phase and uplift of the eastern Cordillera in the Pliocene (Irving 1975; Cooper et al. 1995; Villamil 1999). The remarkable genetic differentiation and length of isolation in this clade is surprising, given the close geographical proximity to clade $D$, which is also distributed along the eastern Cordillera (the nearest sampled locality is $<50 \mathrm{~km}$ away in Norte Santander; Site: 37, Fig. 5). The two clades are separated from each other by a deep valley, highlighting the efficacy of such landscape features as barriers to gene flow.

In two cases, Adelomyia colonized and persisted in low-elevation Cordilleras geographically isolated from the high Andes. The low-elevation Caribbean Mountains in Venezuela (e.g. Lara-Falcón and Serranía de San Luis ranges) were uplifted during the Miocene and Pliocene (Díaz de Gamero 1977; Ostos et al. 2005; Lallemant \& Sisson 2005; Higgs 2006) and were colonized by Adelomyia around 4.1 Ma (producing the endemic clade $E$ ). The Barquisimeto Depression separates this clade from clade $D$ in the Venezuelan Andes. The isolated low-elevation coastal Cordillera (Chongón-Colonche) of Ecuador was also colonized by Adelomyia, but unlike the coastal Cordilleras in Venezuela, this colonization may have occurred more recently, during the onset of severe glaciations in the Andes (Chaves et al. 2007), which may have forced populations to lower elevations along coastal Ecuador. Alternatively, coastal Ecuador and west Andean populations could have been colonized simultaneously (3.4 Ma), last sharing a recent common ancestor
1.2 Ma, at which point dynamic climate shifts could have isolated this lineage within the Cordillera as glaciers retreated upwards (Chaves et al. 2007).

These two lowland diversification cases certainly merit addressing the assumption that present-day elevations requirements for Adelomyia were the same as those of the past. With this caveat in mind, we suggest Adelomyia has expanded its niche to low-elevation wet forests in coastal Ecuador and coastal Venezuela, and that, it is capable of existing in low-elevation habitats of similar habitat structure to Andean cloud forests in locations where higher elevations are not available.

\section{Synthesis}

Here, we provided evidence for the link between the chronological uplift of the Andes and hummingbird diversification. Our divergence estimates and ancestral biogeographical reconstructions suggest a Miocene origin for the speckled hummingbird Adelomyia melanogenys in the southern portion of central Andes, followed by subsequent colonization of the northern Andes during their early- to-mid-Pliocene uplift phase. The crossvalidation method strongly supported the origin of clade $F$ in the eastern Cordillera of Colombia during the exact time period ( $\sim 3$ to $5 \mathrm{Ma})$, when elevations $>1300 \mathrm{~m}$ required by Adelomyia were achieved. Andean clades $B, C$ and $D$ appear to have experienced severe population bottlenecks as a result of range shifts and contractions influenced by climatic fluctuations during the Pleistocene, followed by population expansion in more recent times. The pre-Pleistocene origin of the six extant lineages in the Andes supports the hypothesis that uplift during this epoch was a driving factor in the diversification in Adelomyia.

\section{Acknowledgements}

We thank the following institutions and people for contributing to this research: Field work was possible by the outstanding effort of José Hidalgo, Esteban Neumann, Mauricio Ugarte Lewis, Oscar Gonzalez, Jhonathan Miranda, Maya Yanover, Vanesa Serrudo, Matthew Gracey, Eberth Ledezma, Magaly Acuña, Adrian Gonzalez, Claudia Moncagatta and Fernando Barrantes. Ryan Harrigan and Henry Thomassen provided constructive comments on earlier drafts of the manuscript. We thank the curators at the following museums for access to specimens and permits: The Louisiana State University Museum of Natural Science (J.V. Remsen, Robb Brumfield and Donna Dittmann), The Humboldt Institute in Colombia (Diana López), Museo Nacional de Historia Natural in Bolivia (Isabel Gomez) and finally to the Colección Ornitológica W.H. Phelps in Venezuela (Jorge Pérez). Methods for sampling were approved by UCLA's Animal Research Protocol (A3196-01). Funding was made possible through support from: The Miguel Velez Endowment Fund, Sigma Xi, The Explorers Club, UCLA 
Latin American Institute, Lida Scott Brown Fund, Frank M. Chapman Memorial Fund-American Museum of Natural History, and Grants from NSF (IRCEB9977072) and NASA (IDS/03-0169-0347) to TBS. We are grateful to the nations of Bolivia, Ecuador and Peru for approving our collecting and research programme.

\section{References}

Bates J, Zink RM (1994) Evolution into the Andes: molecular evidence for species relationships in the genus Leptopogon. The Auk, 111, 507-515.

Bleiweiss R (1998) Origins of hummingbird faunas. Biological Journal of the Linnean Society, 65, 77-97.

Bonaccorso E (2009) Historical biogeography and speciation in the Neotropical highlands: molecular phylogenetics of the jay genus Cyanolyca. Molecular Phylogenetics and Evolution, 50, 618-632.

Brumfield RT, Capparella AP (1996) Historical diversification of birds in northwestern South America: a molecular perspective on the role of vicariant events. Evolution, 50, 1607-1624.

Brumfield RT, Edwards SV (2007) Evolution into and out of the Andes: a Bayesian analysis of historical diversification in Thamnophilus antshrikes. Evolution, 61, 346-367.

Buermann W, Saatchi S, Smith TB et al. (2008) Predicting species distributions across the Amazonian and Andean regions using remote sensing. Journal of Biogeography, 35, 1160-1176.

Cadena CD, Klicka J, Ricklefs RE (2007) Evolutionary differentiation in the Neotropical montane region: molecular phylogenetics and phylogeography of Buarremon brushfinches (Aves, Emberizidae). Molecular Phylogenetics and Evolution, 44, 993-1016.

Chaves JA, Smith TB (2011) Evolutionary patterns of diversification in the Andean hummingbird genus Adelomyia. Molecular Phylogenetics and Evolution, 60, 207-218.

Chaves JA, Pollinger J, Smith TB, LeBuhn G (2007) The role of geography and ecology in shaping the phylogeography of the speckled hummingbird (Adelomyia melanogenys) in Ecuador. Molecular Phylogenetics and Evolution, 43, 795-807.

Chesser RT (2000) Evolution in the high Andes: the phylogenetics of Muscisaxicola ground-tyrants. Molecular Phylogenetics and Evolution, 15, 369-380.

Chesser RT, Zink RM (1994) Modes of speciation in birds: a test of Lynch's method. Evolution, 48, 490-497.

Cooper MA, Addison FT, Alvarez R et al. (1995) Basin development and tectonic history of the Llanos Basin, Eastern Cordillera, and Middle Magdalena Valley, Colombia. The American Association of Petroleum Geologists Bulletin, 79, 1421-1443.

Cracraft J (1985) Historical biogeography and patterns of differentiation within the South American avifauna: areas of endemism. Neotropical Ornithology, 36, 49-84.

Díaz de Gamero ML (1977) Estratigrafía y micropaleontología del Oligoceno y Mioceno inferior del centro de la Cuenca del Falcón, Venezuela. GEOS, 22, 3-60.

Dickinson E (2003) The Howard \& Moore complete checklist of the birds of the world. 3rd edition. Princeton University Press, Princeton, NJ.
Dingle C, Lovette IJ, Canaday C, Smith TB (2006) Elevational zonation and the phylogenetic relationships of the Henicorhina wood-wrens. The Auk, 1232, 119-134.

Doan TM (2003) A south-to-north biogeographic hypothesis for Andean speciation: evidence from lizard genus Proctoporus (Reptilia, Gymnophthalmidae). Journal of Biogeography, 30, 361-374.

Drummond AJ, Rambaut A (2007) BEAST: Bayesian evolutionary analysis by sampling trees. BMC Evolutionary Biology, 7, 214.

van den Elzen R, Guillen J, Ruiz-del-Valle V et al. (2001) Both morphological and molecular characters support speciation of South American siskins by sexual selection. Cellular and Molecular Life Sciences, 58, 2117-2128.

Excoffier L, Smouse P (1994) Using allele frequencies and geographic subdivision to reconstruct gene genealogies within a species: molecular variance parsimony. Genetics, 136, 343-359.

Excoffier L, Laval G, Schneider S (2005) Arlequin ver. 3.0: an integrated software package for population genetics data analysis. Evolutionary Bioinformatics Online, 1, 47-50.

Felsenstein J (1981) Evolutionary trees from DNA sequences: a maximum likelihood approach. Journal of Molecular Evolution, $17,368-376$.

Fjeldså J (1994) Geographical patterns for relict and young species of birds in Africa and South America and implications for conservation priorities. Biodiversity and Conservation, 3, 207-226.

Fjeldså J, Lambin E, Mertens B (1999) Correlation between endemism and local ecoclimatic stability documented by comparing Andean bird distributions and remotely sensed land surface data. Ecography, 22, 63-78.

Fu XY (1997) Statistical tests of neutrality of mutations against population growth, hitchhiking and background selection. Genetics, 147, 915-925.

García-Moreno J, Fjeldså J (2000) Chronology and mode of speciation in the Andean avifauna. In: Isolated Vertebrate Communities in the Tropics (ed. Rheinwald G), pp. 25-46. Proceedings of the 4th International Symposium of Zoologisches Forschungsinstitut und Museum A. Koenig, Bonn, Germany.

García-Moreno J, Arctander P, Fjeldså J (1999a) Strong diversification at the treeline among Metallura hummingbirds. The Auk, 116, 702-711.

García-Moreno J, Arctander P, Fjeldså J (1999b) A case of rapid diversification in the Neotropics: phylogenetic relationships among Cranioleuca spinetails (Aves, Furnariidae). Molecular Phylogenetics and Evolution, 12, 273-281.

Garzione CN, Hoke GD, Libarkin JC et al. (2008) Rise of the Andes. Science, 320, 1304-1307.

Goldman N, Anderson JP, Rodrigo AG (2000) Likelihoodbased tests of topologies in phylogenetics. Systematic Biology, $49,652-670$.

Graham CH, Ron SR, Santos JC, Schneider CJ, Moritz C (2004) Integrating phylogenetics and environmental niche models to explore speciation mechanisms in Dendrobatid frogs. Evolution, 58, 1781-1793.

Graham CH, Silva N, Velásquez-Tibatá J (2010) Evaluating the potential causes of range limits of birds of the Colombian Andes. Journal of Biogeography, 37, 1863-1875. 
Graves GR (1985) Elevational correlates of speciation and intraspecific geographic variation in plumage in Andean forest birds. The Auk, 102, 556-579.

Graves GR (1988) Linearity of geographic range and its possible effect on the population structure of Andean birds. The Auk, 105, 47-52.

Gregory-Wodzicki KM (2000) Uplift history of the Central and Northern Andes: a review. Geological Society of America Bulletin, 112, 1091-1105.

van der Hammen T (1989) History of the montane forests of the northern Andes. Plant Systematics and Evolution, 162, 109-114.

Harris AJ, Xiang Q-Y (2009) Estimating ancestral distributions of lineages with uncertain sister groups: a statistical approach to Dispersal-Vicariance Analysis and a case using Aesculus L. (Sapindaceae) including fossils. Journal of Systematics and Evolution, 47, 349-368.

Hartley A (2003) Andean uplift and climate change. Journal of the Geological Society, 160, 7-10.

Higgs R (2006) Colombia-Venezuela-Trinidad "Caribbean Oblique Collision Model" revised: Sociedad Venezolana de Geofísicos, XIII Congreso Venezolano de Geofísica, Caracas, Memorias CD.

Hilty SL, Brown WL (1986) A Guide to the Birds of Colombia. Princeton University Press, Princeton, NJ.

Hooghiemstra H, van der Hammen T (2004) Quaternary IceAge dynamics in the Colombian Andes: developing an understanding of our legacy. Philosophical Transactions of the Royal Society of London B, 359, 173-180.

Hooghiemstra H, Wijninga VM, Cleef AM (2006) The paleobotanical records of Colombia: implications for biogeography and biodiversity. Annals of the Missouri Botanical Garden, 96, 297-325.

Hoorn C, Wesselingh FP, ter Steege $\mathrm{H}$ et al. (2010) Amazonia through time: Andean uplift, climate change, landscape evolution, and biodiversity. Science, 330, 927-931.

Huelsenbeck JP, Hillis DM, Nielsen R (1996) A likelihood-ratio test of monophyly. Systematic Biology, 45, 546-558.

Hughes C, Eastwood R (2006) Exceptional rates of plant diversification after uplift of the Andes. Proceedings of the National Academy of Sciences, 103, 10334-10339.

Irving EM (1975) Structural evolution of the northernmost Andes, Colombia. U.S. Geological Survey Professional Papers, $846,47$.

Johnson NK, Jones RE (2001) A new species of Tody-Tyrant (Tyrannidae: Poecilotriccus) from Northern Peru. The Auk, 118, 334-341.

Kroonenberg SB, Bakker JGM, van der Wiel AM (1990) Late Cenozoic uplift and paleogeography of the Colombian Andes: constraints on the development of high Andean biota. Geologie en Mijnbouw, 69, 279-290.

Lallemant AHG, Sisson VB (2005) Exhumation of eclogites and blueschists in northern Venezuela: constraints from kinematic analysis of deformation structures. In: Caribbean/South American Plate Interactions, Venezuela (eds Lallemant AHG, Sisson V), pp. 193-206. Geological Society of America Special Paper, 394.

McGuire JA, Witt CC, Altshuler DL, Remsen JV (2007) Phylogenetic systematics and biogeography of hummingbirds: Bayesian and maximum likelihood analyses of partitioned data and selection of an appropriate partitioning strategy. Systematic Biology, 56, 837-856.
Milá B, Wayne RW, Smith TB (2009) Divergence with gene flow and fine-scale phylogeographical structure in the wedge-billed woodcreeper, Glyphorynchus spirurus, a Neotropical rainforest bird. Molecular Ecology, 18, 2979-2995.

Miller M, Bermingham E, Ricklefs R (2007) Historical biogeography of the new world solitaires (Myadestes spp.). The Auk, 124, 868-885.

Mora A, Parra M, Strecker MR et al. (2008) Climatic forcing of asymmetric orogenic evolution in the Eastern Cordillera of Colombia. Geological Society of America Bulletin, 120, 930949.

Moritz C, Patton JL, Schneider CJ, Smith TB (2000) Diversification of rainforest faunas: an integrated molecular approach. Annual Review of Ecology and Systematics, 31, 533563.

Noble DC, McKee EH, Mourier T, Mégard F (1990) Cenozoic stratigraphy, magmatic activity, compressive deformation, and uplift in northern Peru. Geological Society of America Bulletin, 102, 1105-1113.

Nylander JAA, Olsson U, Alström P, Sanmartín I (2008) Accounting for phylogenetic uncertainity in biogeography: a Bayesian approach to dispersal-vicariance analysis of the thrushes (Aves:Turdus). Systematic Biology, 57, 257-268.

Olson DM, Dinerstein E, Wikramanayake ED et al. (2001) Terrestrial ecoregions of the world: a new map of life on earth. BioScience, 51, 933-938.

Ostos M, Yoris F, Lallemant HG (2005) Overview of the southeast Caribbean-South American plate boundary. Geological Society of America Special Papers, 394, 53-86.

Parker III TA, Schulenberg TS, Graves GR, Braun MJ (1985) The avifauna of the Huancabamba region, Northern Peru. In: Neotropical Ornithology (eds Buckley PA, Foster MS, Morton ES, Ridgely RS, Buckley FG), pp. 169-197. Ornithological Monographs 36.

Pérez-Emán JL (2005) Molecular phylogenetics and biogeography of the Neotropical redstarts (Myioborus; Aves, Parulinae). Molecular Phylogenetics and Evolution, 37, 511-528.

Picard D, Sempere T, Plantard O (2008) Direction and timing of uplift propagation in the Peruvian Andes deduced from molecular phylogenetics of highland biotaxa. Earth and Planetary Science Letters, 271, 326-336.

Posada D (2008) jModelTest: phylogenetic model averaging. Molecular Biology and Evolution, 25, 1253-1256.

Poulsen CJ, Ehlers TA, Insel N (2010) Onset of convective rainfall during gradual late Miocene rise of the Central Andes. Science, 328, 490-493.

Rambaut A, Drummond AJ (2003) Tracer v.1.3. Available at: http:/ / beast.bio.ed.ac.uk/Tracer.

Rambaut A, Grassley N (1997) Seq-Gen: an application for Monte Carlo simulation of DNA sequence evolution along phylogenetic trees. Computer Applications in the Biosciences, 13, 235-238.

Ramos-Onsins SE, Rozas J (2002) Statistical properties of new neutrality tests against population growth. Molecular Biology and Evolution, 19, 2092-2100.

Räsänen ME, Salo JS, Kalliola RJ (1993) Fluvial perturbance in the western Amazon Basin: regulation by long-term subAndean tectonics. Science, 238, 1398-1401.

Ribas CC, Moyle RG, Miyaki CY, Cracraft J (2007) The assembly of montane biotas: linking Andean tectonics and climatic oscillations to independent regimes of diversification 
in Pionus parrots. Proceedings of the Royal Society B: Biological Sciences, 274, 2399-2408.

Ronquist F, Huelsenbeck JP (2003) MRBAYES 3: Bayesian phylogenetic inference under mixed models. Bioinformatics, 19, 1572-1574.

Schuchmann KL (1999) Family Trochilidae (Hummingbirds). Lynx Edicions, Barcelona.

Simpson BB (1979) Quaternary biogeography of the high montane regions of South America. In: The South American Herpetofauna: Its Origin, Evolution, and Dispersal (ed. Duellman WE), pp. 157-188. Monographs of the Museum of Natural History, University of Kansas 7.

Smith BT, Klicka J (2010) The profound influence of the Late Pliocene Panamanian uplift on the exchange, diversification, and distribution of New World birds. Ecography, 33, 333-342.

Stattersfield AJ, Crosby MJ, Long AJ, Wege DC (1998) Endemic Bird Areas of the World. Birdlife International, Cambridge, UK.

Swofford DL (2000) PAUP*: Phylogenetic Analysis Using Parsimony (* and Other Methods). Ver 4.0b4a. Sinauer Associates, Sunderland, MA.

Villamil T (1999) Campanian-Miocene tectonostratigraphy, depocenter evolution and basin development of Colombian and western Venezuela. Palaeogeography, Palaeoclimatology, Palaeoecology, 153, 239-275.

Weir JT (2006) Divergent timing and patterns of species accumulation in lowland and highland Neotropical birds. Evolution, 60, 842-855.

Weir JT (2009) Implications of genetic differentiation in Neotropical montane forest birds. Annals of the Missouri Botanical Garden, 96, 410-433.

Weir JT, Schluter D (2008) Calibrating the avian molecular clock. Molecular Ecology, 17, 2321-2328.

Weir JT, Bermingham E, Schluter D (2009) The Great American Biotic Interchange in birds. Proceedings of the National Academy of Sciences, USA, 106, 21737-21742.
Weir JT, Bermingham E, Miller MJ, Klicka J, González MA (2008) Phylogeography of a morphologically diverse Neotropical montane species, the common bush-tanager (Chlorospingus ophthalmicus). Molecular Phylogenetics and Evolution, 47, 650-664.

Wilcox TP (2004) SG Runner 1.5.2: A MAC OS X shell-wrapper for Seq-Gen.

Yu Y, Harris AJ, Xingjin H (2010) S-DIVA (Statistical DispersalVicariance Analysis): a tool for inferring biogeographic histories. Molecular Phylogenetics and Evolution, 56, 848-850.

\section{Data accessibility}

GenBank accession numbers for all sequences are given in the Supporting Information associated with the online version of this manuscript.

\section{Supporting information}

Additional supporting information may be found in the online version of this article.

Appendix S1 Specimen data.

Appendix S2 The Bayesian posterior probability (BPP), the ML bootstrap support and estimated divergence times from BEAST for each node (nodes I to V as in Fig. 3).

Please note: Wiley-Blackwell are not responsible for the content or functionality of any supporting information supplied by the authors. Any queries (other than missing material) should be directed to the corresponding author for the article. 